\title{
APPLICATION OF THE INDEPENDENT SUBSECTIONS METHOD FOR THE ESTIMATION OF THE RATING CURVE IN THE COMPOUND CHANNEL - A CASE STUDY
}

\author{
DEJANA ĐORĐEVIĆ(1), NEMANJA ĐUROVIĆ(2),PETARĐURIĆ(3), FILIP STANIĆ(4) \& NIKOLA MILINKOVIĆ(5) \\ (1), (2), (3) University of Belgrade, Faculty of Civil Engineering, Belgrade, Serbia \\ dejana@grf.bg.ac.rs, djurovski90@gmail.com, djuricpetar@gmail.com \\ ${ }^{(4)}$ Laboratory of hydrology, meteorology and complexity, École des Ponts Paris Tech University, France \\ fillip.stanic@enpc.fr \\ ${ }^{(5)}$ nikmil@gmail.com
}

\begin{abstract}
The independent subsections model (ISM) was developed for the steady uniform and non-uniform flow computations in compound channels with constant and variable channel widths. It was thoroughly tested against experimental data in different compound channel layouts. Since the existing set of equations is derived for the simple compound channel geometry, this paper aims at: 1) extending the model to arbitrary geometries, 2) adding the term that accounts for the influence of emergent rigid floodplain vegetation into momentum equations and 3) at validating the method against available floods data from one river gauging station. Comparison with the recorded data has shown that the optimal value for the model parameter $\psi^{t}=0.10$ is greater than that obtained for the canal with smooth floodplains. Partial head losses due to vegetation are two orders of magnitude greater than the friction loss for $\mathrm{H}_{*}>0.25$ when they are calculated with the formula for the volume drag force caused by an array of emergent rigid vegetation, proposed by Nepf,. The head loss due to a drag grows faster with the increase in floodplain submergence ratio on the floodplain with the constrained width. In the presence of vegetation on the floodplains, the head loss caused by mass exchange due to non-prismaticity of the compound channel does not depend on the floodplain width. This component of the head loss is balanced with the sum of head losses due to turbulence diffusion and vegetation drag.
\end{abstract}

Keywords: Non-prismatic compound channel, energy loss, volume drag force exerted by rigid-stem vegetation

\section{INTRODUCTION}

In non-prismatic river channels with cross-sections of an arbitrary shape, a non-uniform roughness, caused by different types of land-use and occupation, adds to the complexity of the flow field when the overbank flow occurs. Although the cross-section of a compound river channel is divided into hydraulically homogeneous subsections, the momentum conservation equation in the traditional Divided Channel Method (DCM) is written and solved for the entire cross-section. Such an approach is based on the assumption that head loss gradients are equal in all subsections. A number of laboratory experiments that have been performed since the constitution of the IAHR Working group on compound channels (Ikeda and McEwan, 2009, Bousmar et al. 2004, 2006; Proust et al. 2006, 2009, 2013, Das and Khatua, 2018) have proven such an assumption can provide neither realistic discharge distribution between the main channel (MC) and floodplains (FPs), nor the water level in a compound channel. Inspired by the work of Yen et al. form 1985, Proust et al. (2009) tried to overcome this drawback by writing mass and momentum equations for each subsection. In this manner, they explicitly accounted for the interaction between the adjacent subsections by introducing mass and momentum exchanges at the interface between subsections into corresponding equations. This enabled simultaneous estimation of the water surface profiles in each subsection. The method was named Independent Subsections Method (ISM). It was tested against more than 46 experiments (Proust at al. 2016) with different: 1) compound channel layouts (symmetrical and asymmetrical, prismatic and non-prismatic), 2) floodplain roughness (smooth and rough) and 3) floodplain submergence ratios. The resulting maximum relative error for the calculated flow depth in experiments with smooth floodplains was $8 \%$ and that for the mean subsection's velocity, 19\% (Proust et al. 2016). These discrepancies are much lower than for the traditional DCM which overestimates both the total and the main channel discharges and underestimates those on the floodplains for high floodplain submergence ratios $\left(H_{\star}=h_{f p}\right.$ / $H>$ 0.3, see Fig.1; Bousmar and Zech, 1999; Đorđević et al., 2015). The overestimation of the main channel discharge can be as high as $60 \%$ for the highest $H_{*}$-values. This makes ISM advantageous over DCM "when an accurate prediction of both water level and discharge distribution between MC and FP is required" (Proust et al, 2016). ). In the case of rough floodplains these discrepancies become greater (Proust et al, 2016). However, no 
quantitative measure for the agreement between calculated and measured water surface profiles and discharge distributions is given, except that for the interfacial Reynolds

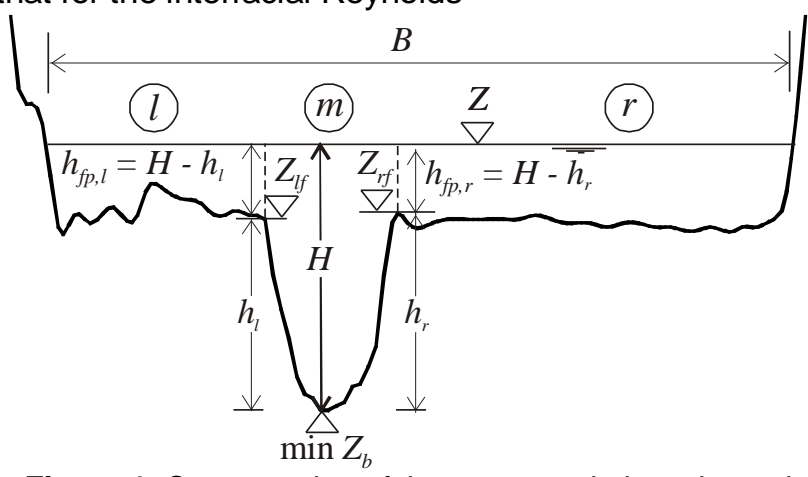

Figure 1. Cross-section of the compound, river channel

stress, which plays an important role in the momentum exchange between the MC and FPs. The maximum relative error for the case when meadows on the floodplain are succeeded by the wood is 27\% (Proust et al. 2016). It should be noted that experiments with rough floodplains (covered with meadows, wood and the combination of the two in the streamwise direction) were performed in the prismatic compound channel.

In Proust et al.'s experiments with non-prismatic (skewed) channel layouts, all subsections were rectangular and the corresponding form of the ISM was developed for the simple subsection geometry. Thus, the aim of this paper is to further extend the ISM to arbitrary subsection geometries and to validate the method against available floods observation data from one river gauging station in Serbia. In addition to the assessment of the model performance in estimating the rating (stage-discharge) curve, contributions of different sources of energy dissipation to the total head loss are also assessed. They include: 1) the bed friction, 2) the turbulent momentum flux, 3) the momentum flux due to mass exchange and 4) the volume drag force exerted by rigid-stem vegetation.

\section{GOVERNING EQUATIONS}

To account for different sources of head losses that arise for overbank flows, Proust et al, (2009) divided the cross section of a compound channel into hydraulically homogeneous subsections. Generally, there are three subsections - the main channel (subscript " $m "$ ), and two floodplains (left and right, subscripts " $r$ and " $r$ ", respectively). The mass and momentum conservation equations are then written for each subsection. However, these equations are not independent. Both mass and momentum equations are linked by lateral mass discharges per unit length. Momentum equations are additionally linked by momentum transfer through the interface between adjacent parallel subsections. For steady flow, the three mass conservation equations:

$$
\frac{\partial Q_{l}}{\partial x}=-q_{l m}, \quad \frac{\partial Q_{r}}{\partial x}=-q_{r m}, \quad \frac{\partial Q_{m}}{\partial x}=q_{l m}+q_{r m}
$$

can be combined into a single one for the whole compound channel cross-section:

$$
\frac{\partial Q_{l}}{\partial x}+\frac{\partial Q_{r}}{\partial x}+\frac{\partial Q_{m}}{\partial x}=0
$$

where $Q_{l}, Q_{r}$ and $Q_{m}$ are subsection discharges; $q_{l m}$ and $q_{r m}$ are lateral mass discharges per unit length through the interface between the left FP and the MC, and the right FP and the MC, respectively. Thus the system of coupled equations consists of one mass conservation equation and the following three momentum equations:

$$
\frac{\partial}{\partial x}\left(A U^{2}\right)_{i}+g A_{i} \frac{\partial Z}{\partial x}+g A_{i} S_{f, i}-q_{i n, i} U_{\text {in }, i}+q_{\text {out }, i} U_{\text {out }, i} \mp \frac{\tau_{i j} h_{\text {int } i}}{\rho}+\kappa_{\text {veg }} \frac{a C_{D} A_{i} U_{i}^{2}}{2}=0, i=l, r, m
$$

The momentum equations are written under the assumption that the water surface is horizontal in the entire crosssection of the compound channel. The first term in Eq. 3 is convective acceleration; the second one describes pressure and gravity forces; the third one, the friction force; the forth and the fifth terms describe components of the force of inertia by which the considered subsection acts on the adjacent one and that by which the adjacent subsection acts on the one for which the equation is written; the sixth one is the apparent shear force between adjacent subsections $i$ and $j$, and the last one describes the drag force exerted by rigid vegetation stems. The space coordinate $x$ in the streamwise direction is the independent variable; $A_{i}$ is the subsection flow area; $U_{i}$ is the 
subsection mean velocity, $S_{f, i}$ is the subsection friction slope, $q_{i n, i}$ and $q_{\text {out }, i}$ are lateral mass discharges per unit length that enter $\left(q_{i n, i}\right)$ and leave $\left(q_{\text {out }, i}\right)$ the subsection with streamwise velocities $U_{i n, i}$ and $U_{\text {out }, i}$, respectively; $\tau_{i j}$ is the apparent shear stress that acts at the interface between subsections $i$ and $j ; h_{\text {int }, l}$ and $h_{\text {int }, \text { rare flow depths at }}$ the interface between the MC and left FP and the MC and the right FP, respectively; $U_{\text {int }, l}$ and $U_{\text {int, } r}$ are streamwise depth averaged velocities at interfaces with the left and right FPs; $a$ is the frontal area of vegetation stems per unit volume, $C_{D}$ is the drag coefficient of the individual stem and $\kappa_{v e g}$ is the parameter which is equal 1 on floodplains where vegetation grows and it is 0 in the main channel.

With the aid of subsection mass conservation equations and by following the similar procedure to that described by Proust et al. (2009) for a rectangular subsection, the subsection momentum equations (3) can be transformed to:

$$
\begin{aligned}
& \left(1-\frac{U_{l}^{2} B_{l}}{g A_{l}}\right) \frac{\partial Z}{\partial x}=-S_{f, l}+\frac{U_{l}^{2}}{g A_{l}}\left(\frac{\mathrm{d} A_{l}}{\mathrm{~d} x}\right)_{Z=\mathrm{const}}+\frac{\tau_{l m} h_{\mathrm{int}, l}}{\rho g A_{l}}-\frac{a C_{D} U_{l}^{2}}{2 g}+\frac{q_{l m}\left(2 U_{l}-U_{\mathrm{int},}\right)}{g A_{l}} \\
& \left(1-\frac{U_{r}^{2} B_{r}}{g A_{r}}\right) \frac{\partial Z}{\partial x}=-S_{f, r}+\frac{U_{r}^{2}}{g A_{r}}\left(\frac{\mathrm{d} A_{r}}{\mathrm{~d} x}\right) Z=\mathrm{const}+\frac{\tau_{r m} h_{\mathrm{int}, r}}{\rho g A_{r}}-\frac{a C_{D} U_{r}^{2}}{2 g}+\frac{q_{r m}\left(2 U_{r}-U_{\mathrm{int}, r}\right)}{g A_{r}} \\
& \left(1-\frac{U_{m}^{2} B_{m}}{g A_{m}}\right) \frac{\partial Z}{\partial x}=-S_{f, m}+\frac{U_{m}^{2}}{g A_{m}}\left(\frac{\mathrm{d} A_{m}}{\mathrm{~d} x}\right) Z=\mathrm{const}-\frac{\tau_{l m} h_{\mathrm{int},}}{\rho g A_{m}}-\frac{\tau_{r m} h_{\mathrm{int}, r}}{\rho g A_{m}}+\frac{U_{m}^{2}}{g A_{m}}\left(\frac{\mathrm{d} A_{m}}{\mathrm{~d} x}\right) Z=\mathrm{const}- \\
& -\frac{q_{l m}\left(2 U_{m}-U_{\text {int }, l}\right)}{g A_{m}}-\frac{q_{r m}\left(2 U_{m}-U_{\text {int }, r}\right)}{g A_{m}}
\end{aligned}
$$

Unlike equations derived by Proust et al. (2009) for compound channel with rectangular subsections, pressure and gravity forces are not separated in Eqs. (4) - (6), i.e. the piezometric head dZ / $\mathrm{d} x$ is used instead of its components $S_{0}$ and $\mathrm{d} h / d x$. Consequently, the term which takes into account the change in pressure force due to nonprismaticity (the second term on the right hand side) also differs from that in equations derived by Proust et al. $U_{i}^{2} / g B_{i}\left(\mathrm{~d} B_{i} / \mathrm{d} x\right)$. Remaining terms on the right hand side of Eqs (4) - (6) are different components of the head loss: 1) the loss caused by the bed friction, 2) the loss due to momentum exchange induced by turbulence diffusion, 3) the loss originating from the volume drag force exerted by an array of vegetation stems and 4) the loss due to momentum exchange introduced by mass transfer.

The loss due to the bed friction is modeled using Manning's formula for the considered subsection:

$$
S_{f, i}=\frac{n_{i}^{2} U_{i}^{2}}{R_{i}^{4 / 3}}, \quad i=l, r, m
$$

where $n_{i}$ is the Manning's roughness coefficient in the considered subsection and $R_{i}$ is the hydraulic radius. The subsection head loss due to volume drag force originating from an array of rigid vegetation stems is modelled in the same manner as in Proust et al. (2016) by using the expression proposed by Nepf (1999):

$$
S_{D, i}=\frac{a_{i} C_{D, i} U_{l}^{2}}{2 g}, i=l, r
$$

The portion of the head loss caused by lateral momentum transfer originating from turbulence:

$$
S_{t, i}=\frac{\tau_{i j} h_{\mathrm{int}, i}}{\rho g A_{i}}, \quad i=l, r \quad j=m
$$

Is described using the mixing length model that was successfully applied in the exchange discharge model proposed (Bousmar and Zech, 1999), In this model, the apparent shear stress at the interface between the MC and FP is defined by: 


$$
\left|\tau_{i j}\right|=\psi^{t}\left(U_{i}-U_{j}\right), \quad i=l, r \quad j=m
$$

Here again, the $\psi^{t}$ is the coefficient of turbulence exchange, which is considered constant for the given geometry regardless of the variations in hydraulic conditions. The second source of momentum transfer through the interface is the mass exchange, which is calculated using the interface velocities $U_{i n t, i}, i=l, r$ :

$$
\begin{array}{ll}
S_{m, i}=\frac{q_{i m}\left(2 U_{i}-U_{\text {int } i}\right)}{g A_{i}}, i=l, r & \text { for floodpains } \\
S_{m, i}=\sum_{l}^{r} \frac{q_{i m}\left(2 U_{m}-U_{\text {int } i}\right)}{g A_{m}} & \text { for the main channel }
\end{array}
$$

For non-prismatic compound channels with variable overall channel width Proust et I. (2009) propose that the interface velocity is estimated based on the mean velocities in adjacent parallel subsections using weighting coefficients $\varphi_{l}$ and $\varphi_{r}$ :

$$
U_{\text {int }, i}=\varphi_{i} U_{i}+\left(1-\varphi_{i}\right) U_{m}, \quad i=l, r
$$

Values of $\varphi_{l}$ and $\varphi_{r}$ depend on the compound channel layout. Proust et al. (2009) have found that good agreement with measurements is achieved when:

$$
\begin{array}{lc}
\varphi_{i}=4 B_{m} /\left(4 B_{m}+B_{i}\right) & \text { for converging floodplain s } \\
\varphi_{i}=B_{m} /\left(B_{m}+4 B_{i}\right) & \text { for diverging floodplain s }
\end{array}
$$

To define a rating curve at a gauging station, the system of equations (4)-(6) is solved simultaneously for the known piezometric head $\mathrm{d} Z / \mathrm{d} x$. The total compound channel discharge for the given water stage is calculated based on the subsection velocities, i.e. subsection discharges.

\section{SITE DESCRIPTION}

A gauging station on the Tamiš River in Serbia is chosen to validate the ISM in a natural river channel. Tamiš River is the left tributary of the Danube River. Its source is in Carpatian Mountains in Romania. Heavy rains in the snow melting season often induce high flows that can evolve into flash floods. Such floods are serious threat to the main agricultural region in Serbia. To facilitate both irrigation and drainage in this region a complex system with dendritic canal network is made in the region. Moreover, to protect the arable land from flooding river valleys are constrained by embankments. One of the major stems in the network crosses the river $35 \mathrm{~km}$ downstream of the border. The drainage from the upstream side is controlled by sluice gates that had been installed at this node.

The gauging station is located close to the country border (GS1 in Figure 1) where heavy flooding occurred due to a failure of the embankment in 2005. Two bridges cross the river some 10-15 km downstream. This stretch of the river is therefore under the strong backwater effect during high flows. The floodplain between meandering river channel and irregular embankment line was forested in the late 1990ies. Thus, the location of the gauging station offers an opportunity to study different sources of head losses in non-prismatic compound channels - head losses due to turbulence diffusion and mass exchange between the main channel and the floodplain (caused by variable channel width), and those induced by vegetation on the floodplain. The shape of the cross-section at the gauging station and the necessary data for hydraulic analysis are summarised in the table supplied with the Figure 2. As it can be noticed, the change of the floodplain width takes place on different floodplain lengths. The estimated piezometric slope on the study reach is 0.00014 .

\section{CALIBRATION OF MODEL PARAMETERS}

The measure of the goodness of fit between the calculated and the measured data both during calibration of model parameters and model validation was RMSE: 

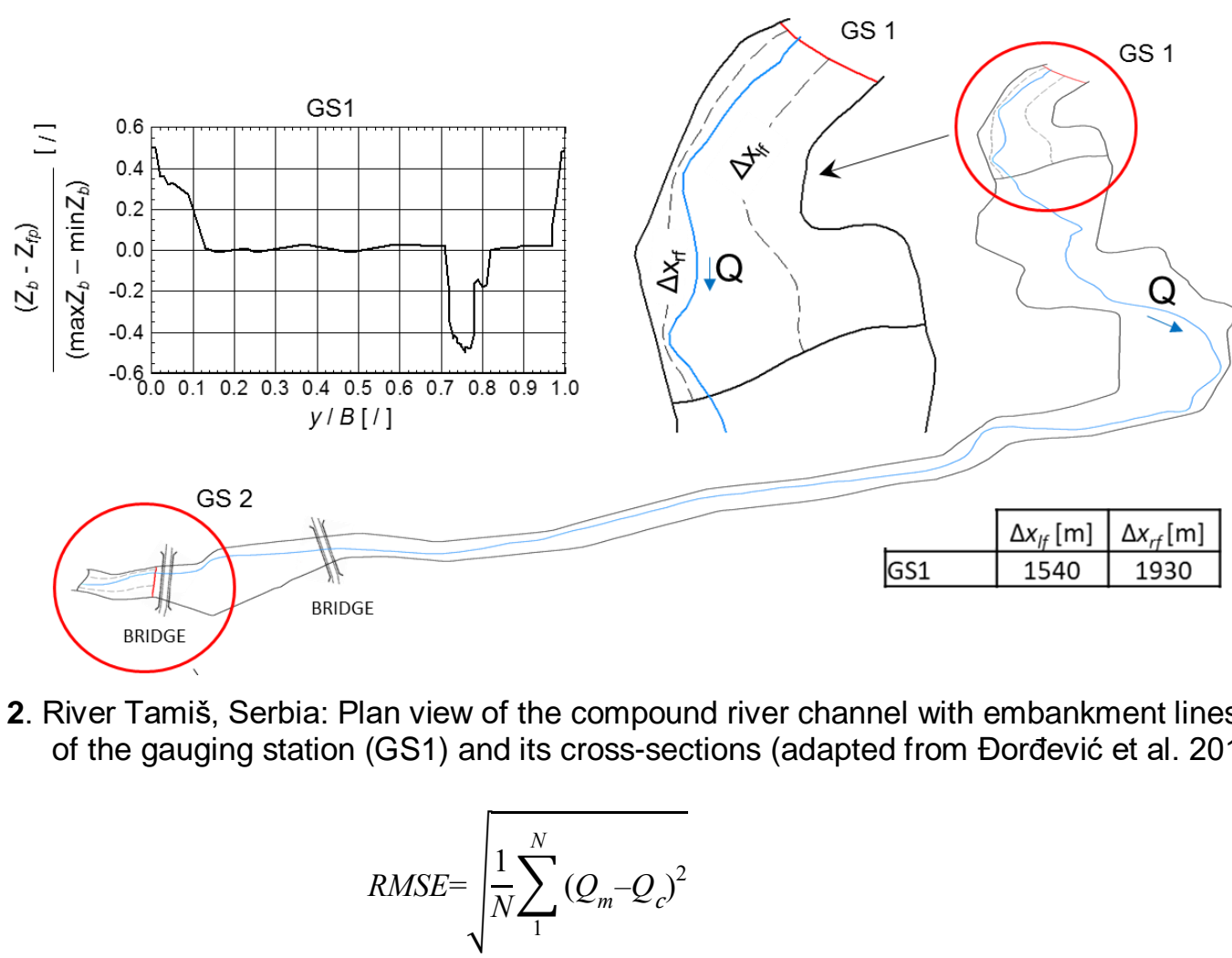

where $Q_{m}$ is the discharge measured at the gauging station, $Q_{c}$ is the discharge calculated by the model, and $N$ is the number of measurements of high flows. The value of the Manning coefficient for the man channel of $n_{m c}=0.020 \mathrm{~m}^{-1 / 3} \mathrm{~s}$ was succeeded from the accompanying paper (Đorđević et al. 2019). The calibration advanced in several steps in the same manner as it was done in the accompanying paper. The Manning's coefficient value for the floodplains $\left(n_{f p}\right)$ was estimated first using the DCM. Such a value included all different sources of head losses. The lowest $R M S E$ value of $43.4 \mathrm{~m}^{3} / \mathrm{s}$ was achieved for $n_{f p}=0.055 \mathrm{~m}^{-1 / 3} \mathrm{~s}$ (Đorđević et al. 2019). A part of the losses was assigned to the turbulence exchange of momentum in the second step by varying the value of parameter $\psi^{t}$. It was found that the optimal $\psi^{t}$-value was 0.10 . This value is larger than that reported by Proust et al. (2009) for laboratory compound channels with smooth floodplains $\left(\psi^{t}=0.02\right)$. Thus, the $n_{f p}$-value was reduced by $40 \%$, i.e. to $n_{f p}=0.033 \mathrm{~m}^{-1 / 3} \mathrm{~s}$. The corresponding $R M S E$-value was approximately $43 \mathrm{~m}^{3} / \mathrm{s}$, or $12 \%$ of the average measured high flow discharge $\left(\overline{Q_{m}}\right)$. By taking into the consideration the effect of the volume drag force exerted by rigid-stem vegetation, the $n_{f p}$-value is further reduced, but to a much smaller extent than in the previous step $\left(n_{f p}=0.033 \mathrm{~m}^{-1 / 3} \mathrm{~s}\right)$. The frontal area of vegetation stems per unit volume $(a)$ was varied between 0.80 and 0.90 and two values of the drag coefficient were considered $\left(C_{D}=1.1\right.$ and $\left.C_{D}=1.2\right)$. The values of $a=$ 0.90 and $C_{D}=1.2$ provided the best agreement between the calculated rating curve and measured discharges. The $R M S E$-value reduced to $32 \mathrm{~m}^{3} / \mathrm{s}$, or to $10 \%$ of the average measured high flow discharge $\left(\overline{Q_{m}}\right)$. The corresponding ISM rating curve is compared with measurements in Fig. $3 \mathrm{a}$ and with DCM in Fig. 3b. The DCM underestimates total compound channel discharge by $6 \%$ on the average, while the average overestimation for ISM amounts $8 \%$. Despite acceptable estimation of the total discharge, the DCM gives the main channel discharge twice as large as that calculated by ISM and approximately $40 \%$ reduced floodplain discharges.

\section{MODEL VALIDATION}

The calibrated $\psi^{t}$-value of 0.10 together with $a=0.90$ and $C_{D}=1.2$ were then used to check the validity of the model on the new measured data set. Results of comparison are presented in Figure 4a. In addition to measured discharges, the DCM and the official rating curve of the Hydrometeorological Service of Serbia are also shown on this Figure. The average discrepancies of the calculated from the measured discharge values are $+14 \%$ for the ISM, $-11 \%$ for the official rating curve and $+8 \%$ for the DCM curve. Despite the fact that the DCM provided the smallest discrepancies, the main channel discharge is overestimated by $84 \%$ on the average, while the left and right floodplain discharges are underestimated by approximately $60 \%$ and $70 \%$ on the average (Fig. $4 \mathrm{~b}$ ). 

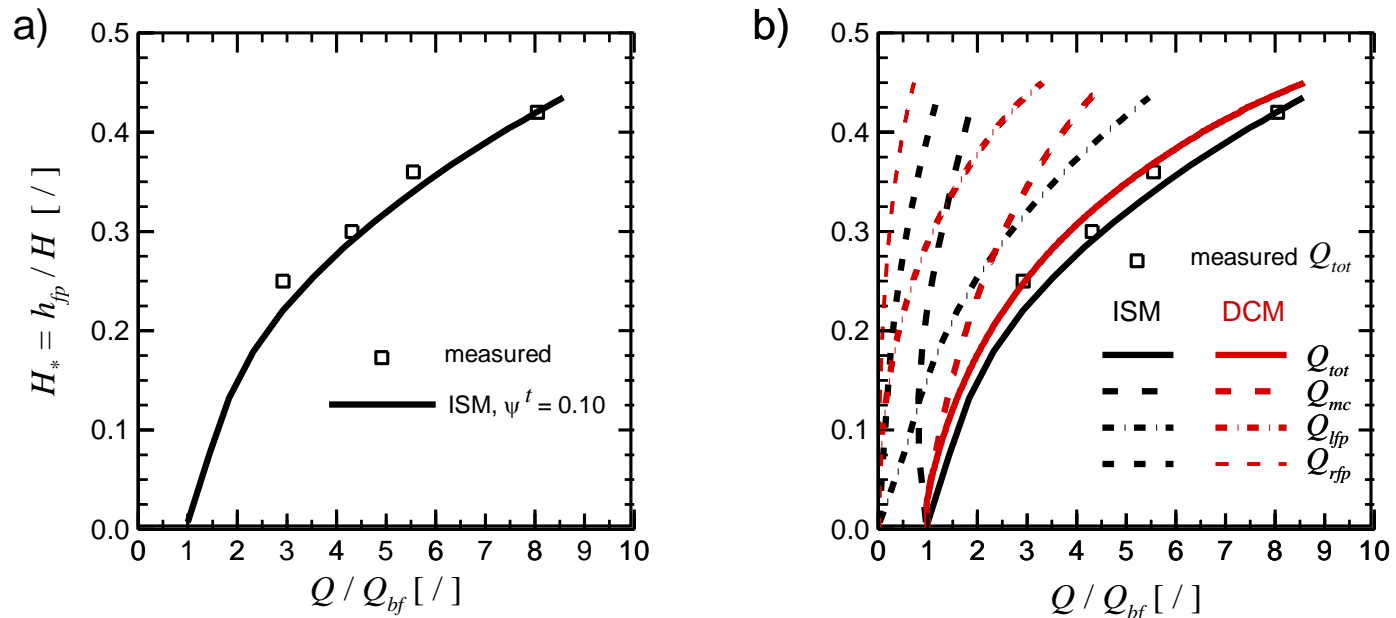

Figure 3. a) Calibration of the ISM parameters; b) comparison of the division of the ISM and DCM total overbank flow discharge $\left(Q_{t o t}\right)$ into the main channel $\left(Q_{m c}\right)$, left and right floodplain discharges $\left(Q_{l f p}\right.$ and $\left.Q_{r f p}\right)$, respectively
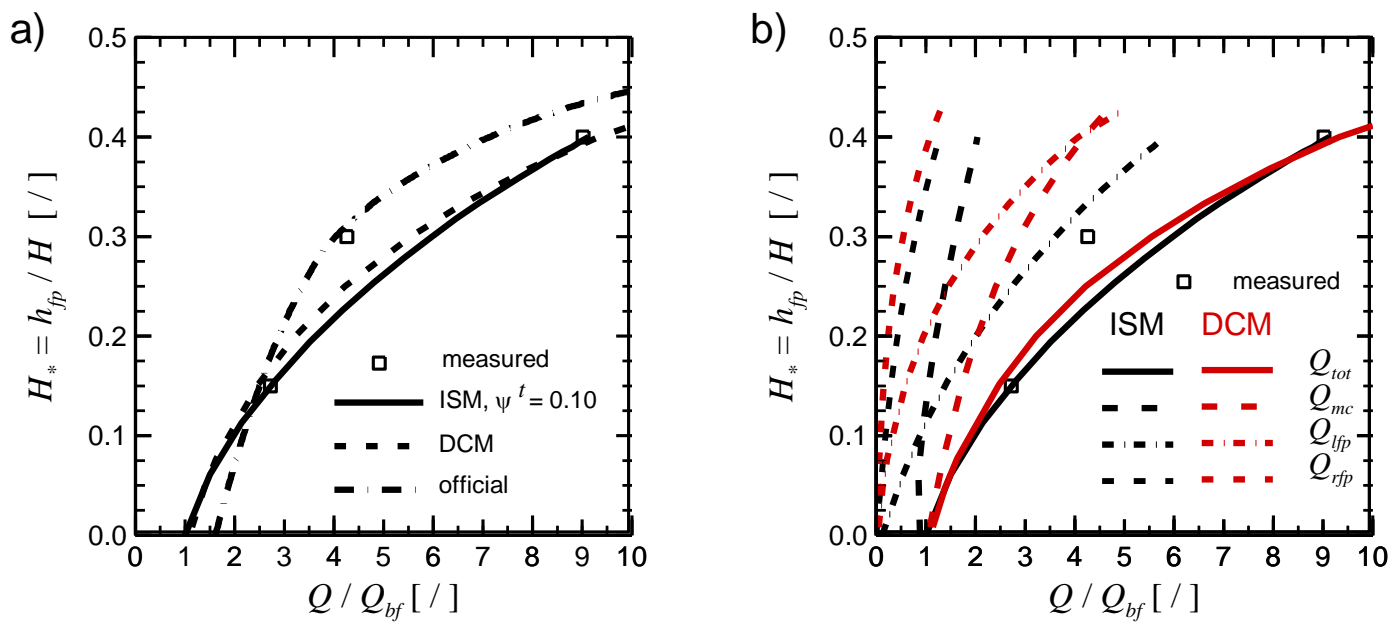

Figure 4. a) Verification of ISM, b) division of the total overbank flow discharge $\left(Q_{t o t}\right)$ into the main channel $\left(Q_{m c}\right)$, left and right floodplain discharges $\left(Q_{l p p}\right.$ and $\left.Q_{r f p}\right)$, respectively

\section{COMPONENTS OF THE TOTAL HEAD LOSS}

A number of laboratory studies, such as those performed by Nepf (1999), Zong and Nepf (2011) and Dupuis (Proust et al. 2016) have shown that the drag force, caused by emergent vegetation, has the most significant contribution to the total head loss in flows obstructed by patches of vegetation. Proust et al. (2016) have shown that for certain discharges the emergent rigid floodplain vegetation can produce head losses that can be almost an order of magnitude greater than friction losses when meadows on the floodplain are succeeded by a wood. Following these observations, head losses by momentum transfer caused by turbulence diffusion $S_{t, i}$, and lateral mass exchange $S_{m, i}$, and those developed by an array (patches) of emergent stems $S_{D, i}$ are compared to the that caused by bed friction $S_{f, i}$. Head losses caused by momentum transfer due to turbulence diffusion are presented in Fig. $5 \mathrm{a}$. It can be noticed that above $\mathrm{H}_{\star}=0.10$ this type of head loss becomes significant. It is an order of magnitude greater than the friction loss for $\mathrm{H}_{*}>0.20$ and it becomes two orders of greater than $S_{f}$ for high floodplain submergence ratios $\left(H_{*}>0.40\right)$. It is interesting to observe that the growth of this type of head loss is limited or negligible in case of wide floodplains covered with vegetation. The head loss caused by mass exchange due to non-prismaticity of the compound channel does not depend on the floodplain width (Fig. 5b). Starting from $\mathrm{H}_{*}=0.25$ the $S_{m, i}$ becomes two orders of magnitudes greater than the friction slope. The same holds for the head loss due to the volume drag force (Fig. 5b). However, the effect of drag grows faster with the increase in floodplain submergence ratio on the floodplain with the constrained width. Results in Figure $5 \mathrm{~b}$ show that the head loss due to mass exchange on the floodplain is balanced with the sum of head losses due to turbulence diffusion and vegetation drag. 

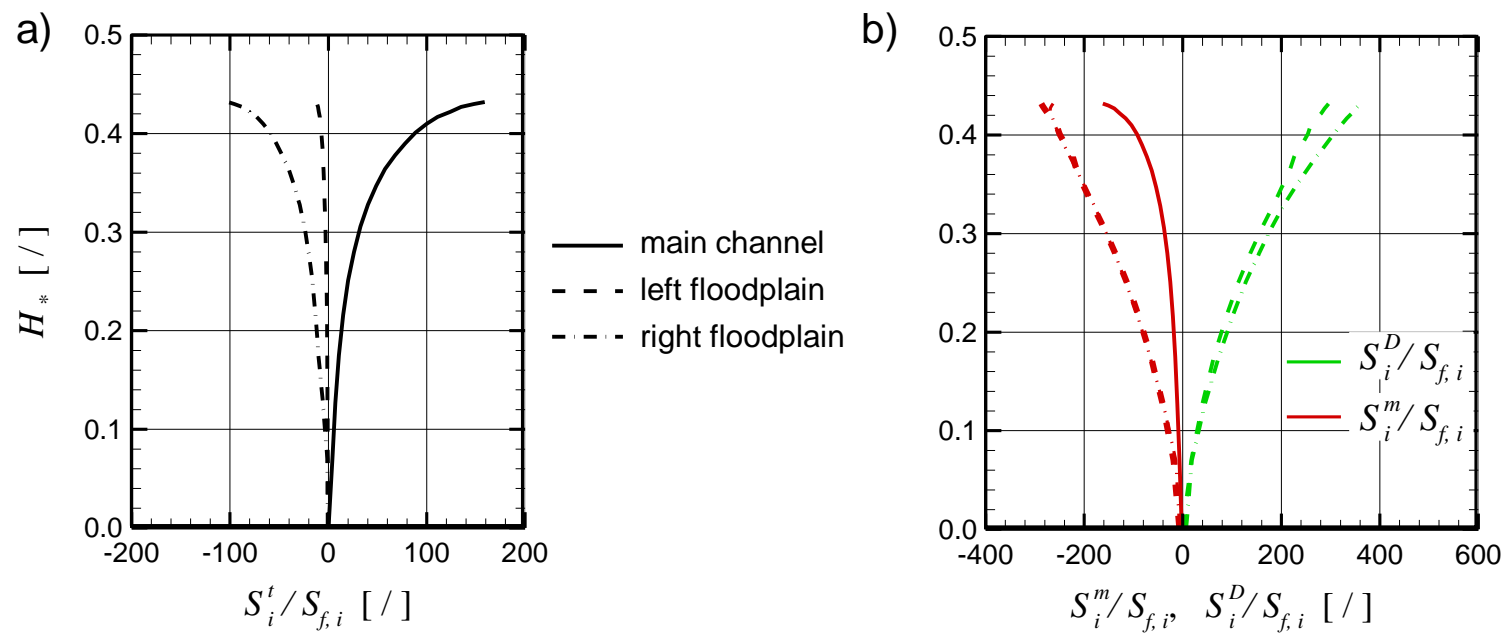

Figure 5. Partial head losses due to a) momentum transfer originating from turbulence diffusion $S_{t, i}$, and

b) momentum transfer caused by mass exchange $S_{m, i}$ and $S_{D, i}$ vegetation drag compared to the friction loss $S_{f, i}$ for different floodplain submergence ratios $H_{\text {* }}$

\section{CONCLUSIONS}

In this paper the Independent Subsections Method, which was developed for steady uniform and nonuniform flow computations in prismatic and non-prismatic compound channels with simple cross-sectional geometry is extended to allow for computations in river channels with cross-sections of arbitrary shape and vegetation on the floodplains. The model is verified using the measured high flow data from a river gauging station. The study has shown that:

i. The model provides satisfactory agreement with the measured high flow discharges when used for the estimation of the rating curve at a river gauging station. The $R M S E$-value is approximately $10 \%$ of the average measured high flow discharge;

ii. The optimal value for the model parameter $\psi^{t}$ that accounts for the effect of turbulence diffusion at the interface between the main channel and the floodplain is 0.10 . This value is larger than that reported by Proust et al. (2009) for laboratory compound channels with smooth floodplains $\left(\psi^{t}=0.02\right)$. The increase in the $\psi^{t}$-value is in line with the discussion by Proust et al. (2016).

iii. The application of the formula for the volume drag force caused by an array of emergent rigid vegetation, proposed by Nepf (1999), produced partial head losses due to vegetation that were two orders of magnitude greater than the friction loss when $\mathrm{H}_{*}>0.25$. This should be further investigated.

iv. The partial head loss due to a drag grows faster with the increase in floodplain submergence ratio on the floodplain with the constrained width.

v. In the presence of vegetation on the floodplains, the head loss caused by mass exchange due to nonprismaticity of the compound channel does not depend on the floodplain width. Moreover, this component of the head loss is balanced with the sum of head losses due to turbulence diffusion and vegetation drag.

\section{ACKNOWLEDGEMENTS}

The research reported herein is funded by the Ministry of Education and Science of the Republic of Serbia (37010).

\section{REFERENCES}

Bousmar, D., and Zech, Y. (1999).Momentum transfer for practical flow computation in compound channels. Journal of Hydraulic Engineering,125(7), 696-706. 
Bousmar, D., Wilkin, N., Jacquemart, J.H. and Zech, Y. (2004). Overbank flow in symmetrically narrowing floodplains. Journal of Hydraulic Engineering, 130(4), 305- 312.

Bousmar, D., Proust, S. and Zech, Y. (2006). Experiments on the flow in a enlarging compound channel. River Flow 2006: Proc. Internat. Conf. on Fluvial Hydraulics, Lisbon, Portugal, Taylor and Francis, Leiden, Netherlands, 323- 332.

Das, B.S. and Khatua, K.K. (2018). Flow resistance in a compound channel with diverging and converging floodplains. Journal of Hydraulic Engineering,144(8), 1-21.

Đorđević, D., Ivković, M. and Stojnić, I. (2019). On the possibilities of application of exchange discharge modelin estimation of a rating curve at a river gauging station. (accepted for Proc. 38th IAHR World Congres, Panama).

Ikeda, S. and McEwan, I.K. (2009). Flow and sediment transport in compound channels. IAHR Monograph

Series.CRC Press, Taylor \& Francis Group, $327 \mathrm{pp}$.

Nepf. H.M. (1999) Drag, Turbulence and diffusion in flow through emergent vegetation. Water Resources Research, 35(2), 479-489.

Proust, S., Riviere, N., Bousmar, D., Paquier, A.,Zech, Y. and Morel, R. (2006).Flow in compound channel with abrupt floodplain contraction. Journal of Hydraulic Engineering,132(9), 958-970.

Proust, S., Bousmar, D., Riviere, N., Paquier, A. and Zech, Y. (2009). Non-uniform flow in compound channel: A 1-D method for assessing water level and discharge distribution. Water Resources Research, 45, W12411.

Proust, S., Fernandes, J.N., Peltier, Y., Leal, J.B. Riviere, N. and Cardoso, A.H. (2013). Turbulent non-uniform flows in straight compound open channels. Journal of Hydraulic Research, 51:6, 656-667.

Zong, L. and Nepf, H. (2011) Spatial distribution of deposition within a patch of vegetation, Water Resources Research, 47, W03516. 